\title{
Modification to the Fontan procedure for the prophylaxis of intra-atrial reentrant tachycardia: Short-term results of a prospective randomized blinded trial
}

\author{
Kathryn K. Collins, MD \\ Edward K. Rhee, $M D^{b}$ \\ Janet M. Delucca, $\mathrm{RN}^{\mathrm{c}}$ \\ Mark E. Alexander, $\mathrm{MD}^{\mathrm{c}}$ \\ Laura M. Bevilacqua, $\mathrm{MD}^{\mathrm{c}}$ \\ Charles I. Berul, MD ${ }^{\mathrm{c}}$ \\ Edward P. Walsh, MD ${ }^{\mathrm{c}}$ \\ John E. Mayer, MD ${ }^{\mathrm{c}}$ \\ Richard A. Jonas, $M^{c}$ \\ Pedro J. del Nido, $M^{\mathrm{C}}$ \\ John K. Triedman, MD
}

From the University of California, ${ }^{a}$ San Francisco, Calif; St Louis Children's Hospital, ${ }^{\text {b }}$ Washington University in St Louis, St Louis, Mo; and Children's Hospital, ${ }^{c}$ Boston, Harvard University, Boston, Mass.

Presented at the American Heart Association meetings in New Orleans, La, November 12-15, 2000.

Received for publication Feb 5, 2003; revisions requested March 25, 2003; revisions received June 2, 2003; accepted for publication June 18, 2003.

Address for reprints: John K. Triedman, MD, Department of Cardiology, Children's Hospital, 300 Longwood Ave, Boston, MA 02115 (E-mail: John.triedman@ cardio. chboston.org)

J Thorac Cardiovasc Surg 2004;127:721-9

$0022-5223 / \$ 30.00$

Copyright () 2004 by The American Association for Thoracic Surgery

doi:10.1016/S0022-5223(03)01055-9
Objectives: We evaluated the feasibility, safety, and short-term efficacy of an interventional atrial incision placed at the time of the Fontan operation to reduce the development of intra-atrial reentrant tachycardia.

Methods: This prospective randomized blinded trial was conducted in patients with congenital heart disease undergoing an initial lateral tunnel Fontan. Intervention patients underwent a lateral tunnel Fontan with an interventional atrial incision/ cryoablation from the atriotomy to the right atrioventricular annulus. Controls underwent a standard lateral tunnel Fontan. Safety of the intervention was monitored. Short-term efficacy was determined by comparisons of conduction block across the incision area and spontaneous or inducible atrial arrhythmias.

Results: There were no significant differences between intervention $(\mathrm{n}=21$, median 2.4 years, range 0.8-3.9) and controls $(\mathrm{n}=21$, median 2.7 years, range 1.5-13.9) in age, type of heart disease, surgical parameters, or postoperative outcomes. Safety parameters showed no difference between groups in number or severity of adverse events. Short-term efficacy included evidence of conduction block with a longer conduction time across the incision area in intervention patients (median $97 \mathrm{~ms}$, range 35-160) compared with controls (median $40 \mathrm{~ms}$, range $8-77, P=.0001$ ). No intervention patients had spontaneous or inducible intra-atrial reentrant tachycardia versus 2 controls $(0 / 21$ versus $2 / 21, P=\mathrm{NS})$.

Conclusions: An interventional atrial incision to reduce intra-atrial reentrant tachycardia in the Fontan operation was feasible and safe. The intervention changed the atrial substrate as shown by an increase in conduction time. Short-term results showed a low incidence of intra-atrial reentrant tachycardia in all patients. Longer follow-up is necessary to assess clinical efficacy.

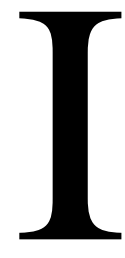

ntra-atrial reentrant tachycardia (IART) is a frequent late complication following the atriopulmonary-type Fontan operation, with an estimated prevalence of $25 \%$ by 5 years and reaching $50 \%$ by 10 years following the operation. ${ }^{1-3}$ Current therapeutic modalities including antiarrhythmic medications, arrhythmia mapping and radiofrequency catheter ablation, ${ }^{4-8}$ and Fontan revision surgery with a right atrial maze creation $^{9-12}$ may provide some patients with improved arrhythmia control. These modalities, however, have 


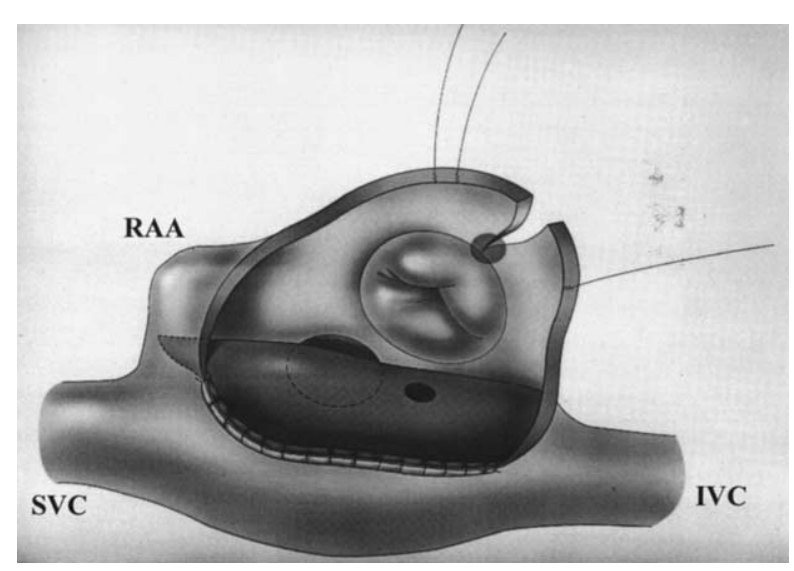

Figure 1. Diagrammatic representation of the lateral tunnel Fontan operation with the interventional atrial incision. The right atrium is opened at the Fontan baffle suture line. The Fontan baffle is fenestrated. The oval with the dashed lines represents the atrial septal defect. The interventional atrial incision was created from the Fontan baffle to the right atrioventricular valve annulus as shown. Cryoablation was used to bring the interventional atrial incision directly to the right atrioventricular valve without causing damage to the right coronary artery (this area is highlighted by a gray circ/e). The placement of the temporary atrial pacing wires are shown, with 2 wires placed superior to the interventional incision and 1 placed inferior to the interventional incision. IVC, inferior vena cava; $S V C$, superior vena cava; $R A A$, right atrial appendage.

limited efficacy or significant side effects and may not be appropriate for all patients. Current techniques of the Fontan procedure involving a lateral tunnel or extracardiac conduit appear to result in a lower incidence of IART ${ }^{13,14}$ but do not entirely eliminate the risk of IART. ${ }^{15-17}$

The mechanisms causing IART in Fontan patients are complex. Based on experience of electrophysiologic studies and radiofrequency ablations in Fontan patients, data from canine models, and initial studies of surgical atrial modifications in Fontan revision patients, the atrial incisions and suture lines of the Fontan operation contribute to the development of IART. In canine models, high-resolution epicardial mapping data has suggested that the atriotomy, the suture lines of the lateral cavopulmonary connection, and the anatomical right atrial boundaries serve as barriers, which themselves constitute a sufficient substrate for the occurrence of IART. ${ }^{18,19}$ Variations in the Fontan suture line with respect to anatomical atrial structures, such as the crista terminalis, have been shown to affect the development of IART circuits. $^{18}$

A prophylactic atrial incision placed in such a way as to disrupt the potential circuits about the atriotomy line has been shown to prevent IART from developing in animal studies. ${ }^{19}$ We hypothesized that an interventional atrial incision, similar to that used in canine models, placed at the time of the initial Fontan operation would cause atrial conduction block, prevent IART circuits from developing around the atriotomy or right atrioventricular annulus, and reduce the overall incidence of IART. This study was designed to: (1) determine the feasibility of placing the interventional incision in patients with heterogeneous anatomy, (2) assess the safety of the intervention, and (3) document short-term efficacy.

\section{Materials and Methods Study Design}

This is a prospective, randomized, double-blinded study in patients with univentricular hearts who underwent the Fontan procedure at Children's Hospital, Boston, between October 1999 and May 2001. The study was approved by the Committee on Clinical Investigation.

\section{Subject Selection}

Criteria for inclusion in this study included: (1) complex congenital heart disease consisting of single ventricle physiology and (2) planned lateral tunnel Fontan operation at Children's Hospital, Boston. Exclusion criteria were: (1) any cardiac anatomy that did not have a clearly defined right atrioventricular annulus (eg, tricuspid atresia) or (2) a history of a prior Fontan operation. An attempt was made to approach and discuss study participation with all patients who fulfilled these criteria and had their Fontan operation during the study period. Informed consent/assent was obtained from the patients and/or their guardians prior to study participation.

\section{Study Intervention}

Patients were randomized to either control or intervention groups. Patients in the control group underwent a conventional lateral tunnel Fontan operation involving an intracardiac baffle created partially by Gore-Tex (W. L. Gore \& Associates, Inc, Flagstaff, Ariz). Fenestration or nonfenestration was determined by the surgeon. The lateral aspect of the Fontan baffle was placed anterior and medial to the crista terminalis. Patients in the intervention group received a standard lateral tunnel Fontan operation with an additional prophylactic atrial incision. (See Figure 1.) The prophylactic atrial incision was placed from the atriotomy line to the right atrioventricular annulus. The superior/inferior orientation of the incision was variable depending on the surgeon's decision as to the best location for the incision and the patient's underlying cardiac anatomy. At the discretion of the surgeon, the prophylactic incision was brought to the atrioventricular groove either with a single 90-second cryothermal lesion (in the majority of cases) or with careful dissection. The incision and atriotomy were then closed with a running Prolene suture. Three temporary atrial epicardial pacing wires were placed on the atrium at the conclusion of the repair for both control and intervention groups. For the intervention group, 2 wires were placed between the atriotomy and the atrioventricular annulus 1 to $1.5 \mathrm{~cm}$ superior to the prophylactic incision and these were brought out together to the thorax on the patient's right side. A third atrial wire was placed 1 to $1.5 \mathrm{~cm}$ inferior to the incision and this single wire was brought to the thorax in the center of the abdomen. This third atrial wire was used 
for assessment of the interventional incision to create conduction block. In control patients, the wires were placed in similar areas as if an intervention had been made.

The rationale for the interventional incision is that it utilizes aspects of the lesion from Rodefeld's ${ }^{19}$ canine studies (incorporation of the atrial suture line and extension of the lesion to the right atrioventricular valve annulus). The advantage of such an interventional incision is that it is a single lesion, is relatively easy to perform, and is likely to carry a low risk of injuring the atrioventricular node. A cryothermal lesion was used as a method of "anchoring" the incision to the nonconducting boundary of the atrioventricular groove. After dissection of the epicardial fat pad, this lesion is placed from the endocardial surface as a method to avoid propagation of the cryothermal injury to the right coronary artery. Patients without a clearly defined right atrioventricular annulus were excluded from the study secondary to concerns that an incision brought to an ill-defined atrioventricular annulus would have a higher potential of causing damage to the right coronary artery and/or the atrioventricular node.

\section{Baseline Measurements}

Baseline evaluation included: (1) documentation of past medical and surgical histories; (2) documentation of prior arrhythmias and arrhythmia therapies; (3) electrocardiogram and 24-hour ambulatory electrocardiogram; (4) echocardiographic parameters of atrioventricular valve regurgitation and qualitative assessment of ventricular function; (5) catheterization data including systemic oxygen saturation, atrial pressure, ventricular end-diastolic pressure, cardiac index, and pulmonary vascular resistance.

\section{Randomization and Blinding}

Randomization was stratified by surgeon, so that each surgeon performed a similar number of intervention and control Fontan operations. Treatment assignment was not revealed until the surgeon had inspected the patient's anatomy in the operating room and assessed that the patient could be included in the study. All parties including subjects, parents, nurses, and investigators were blinded to the intervention with the exception of the operators who performed the intervention and 1 study coordinator.

\section{Operative and Postoperative Parameters}

Surgical parameters of bypass and crossclamp times as well as additional surgical interventions at the time of the Fontan operation were recorded. The primary surgical and medical teams directed intraoperative and postoperative monitoring and care as deemed appropriate. Postoperative parameters of time to extubation, days on inotropic medications, time to removal of chest tubes, length of intensive care unit stay, and length of hospital stay were recorded. Cardiac rhythm evaluation and management were determined by the primary medical/cardiovascular surgical team with the assistance of a pediatric electrophysiologist.

\section{Outcome Measures}

Test of conduction across the interventional incision area. If the prophylactic atrial incision resulted in conduction block, then latency from pacing on 1 side of the incision to sensing on the other involves conduction around the entire atriotomy and should be relatively long. In control patients, or if the prophylactic incision continued to allow conduction, then conduction times across the area would be relatively short. Efficacy of the prophylactic incision in creating a line of conduction block was tested postoperatively using the temporary pacing wires. Atrial overdrive pacing was performed using the 2 superior atrial wires and conduction time to the single inferior wire was then measured. Next, atrial overdrive pacing was performed at the same rate as previously but from the single inferior wire with measurement of atrial activation to the 2 superior atrial wires. The average latency from stimulus to sensed atrial event was recorded as the conduction time.

Spontaneous or inducible intra-atrial reentrant tachycardia. IART was defined as an atrial rhythm with a fixed cycle length and P-wave morphology and with the atrial rhythm being independent of ventricular activation. Spontaneous or clinical IART was documented as to the time from the Fontan operation, any causal factors, and the patient's clinical status. Inducible IART was determined by a postoperative atrial stimulation study that was conducted when the patient was hemodynamically stable and off inotropic support. Atrial stimulation was delivered by a programmable stimulator at twice capture threshold via the 2 superior temporary atrial pacing wires. A standard atrial stimulation protocol was conducted and included: (1) single, double, and triple extrastimuli at a basic cycle length of 600,500 , or $400 \mathrm{~ms}$ (highest that is still shorter than resting cycle length of the patient) and with extrastimulus testing conducted to atrial refractoriness and (2) rapid atrial pacing, 12 beat trains from 400 to $200 \mathrm{~ms}$ in $10-\mathrm{ms}$ increments. If no IART was inducible, then the atrial stimulation protocol was repeated during infusion of isoproterenol at 0.01 to $0.02 \mu \mathrm{g} \cdot \mathrm{kg}^{-1} \cdot \mathrm{min}^{-1}$.

Other supraventricular tachycardia. All other forms of supraventricular tachycardia including ectopic atrial tachycardia, atrioventricular nodal reentry, atrial fibrillation, or accessory pathway-mediated tachycardia were recorded.

Sinus node dysfunction. Sinus node dysfunction was defined as: (1) minimum or mean heart rate more than 2 standard deviations below the age-adjusted mean, (2) predominant junctional rhythm, and/or (3) sinus pause of 3 seconds or more in duration. ${ }^{20}$ The duration of sinus node dysfunction and the need for temporary atrial pacing were documented.

\section{Safety Assessment of Intervention}

Adverse events were categorized according to a standardized list used for reporting in the Cardiac Intensive Care Unit at Children's Hospital, Boston. Severity and likely relationship of adverse events to the study intervention were determined by 3 pediatric cardiologists not directly involved in the study who were blinded to patient name and randomization status.

\section{Statistical Analysis}

Statistical analysis was performed using STATA statistical software (STATA Corporation, College Station, Tex). The 2-sample $t$ test was used for continuous data that were normally distributed, and the Wilcoxon rank-sum test was used for data that are not normally distributed. The chi-square and Fisher exact test were used as appropriate to examine categorical data. 
TABLE 1. Characteristics of patients in intervention and control groups

\begin{tabular}{|c|c|c|c|}
\hline & $\begin{array}{c}\text { Intervention } \\
(\mathrm{n}=21)\end{array}$ & $\begin{array}{c}\text { Control } \\
(n=21)\end{array}$ & $\boldsymbol{P}$ \\
\hline $\operatorname{Sex}(F / M)$ & 9:12 & $12: 9$ & .54 \\
\hline Age (y) & $2.4(0.8-3.9)$ & $2.7(1.5-13.9)$ & .09 \\
\hline Weight (kg) & $10.8(7.4-13.1)$ & $13(8.7-19.1)$ & .03 \\
\hline Height $(\mathrm{cm})$ & $83(67-95)$ & $94(75-122)$ & .01 \\
\hline Cardiac anatomy & & & .35 \\
\hline Hypoplastic left heart syndrome & 9 & 5 & \\
\hline Double-inlet left ventricle & 4 & 5 & \\
\hline Double-outlet right ventricle & 2 & 7 & \\
\hline Pulmonary atresia variants & 3 & 2 & \\
\hline Other & 3 & 2 & \\
\hline Prior cardiac operations & $2(1-3)$ & $2(0-3)$ & .30 \\
\hline
\end{tabular}

Values shown are the absolute count or median (range).

\section{Results}

\section{Patient Demographics}

Forty-two patients were enrolled in the study, divided equally between intervention and control groups. Patient demographics are outlined in Table 1. Patients in the intervention group tended to be older and were significantly taller and heavier than patients in the control group. Most patients had a prior bidirectional cavopulmonary anastomosis (19/21 in the intervention group and 18/21 in the control group). None of the patients had a prior hemi-Fontan procedure.

\section{Preoperative Assessment}

There were no significant differences between groups in any of the preoperative evaluations completed. (See Table 2.) Subjects in both groups had very limited prior arrhythmia history or arrhythmia therapies. Echocardiographic and catheterization parameters showed that most patients were good candidates for the Fontan operation.

\section{Operative and Postoperative Parameters}

There was no difference in bypass time between the intervention group (108 \pm 20 minutes) and the control group $(100 \pm 20$ minutes; $P=.21)$. Crossclamp time was shorter in the intervention group (51 \pm 9 minutes) compared with the control group (58 \pm 14 minutes; $P=.007$ ). All intervention and control patients, except for 1 in the control group, received a fenestrated Fontan procedure. All patients in the intervention group received the interventional incision.

Additional operative procedures in the intervention group included tricuspid valvuloplasty $(\mathrm{n}=4)$, pulmonary artery plasty $(\mathrm{n}=2)$, atrial septectomy $(\mathrm{n}=1)$, and ligation of left superior vena cava to coronary sinus and unroofing of the coronary sinus $(\mathrm{n}=1)$. Additional operative procedures in the control group included atrial septectomy $(n=3)$, division and oversewing of the main pulmonary artery $(\mathrm{n}=$ $2)$, subaortic resection $(n=1)$, ligation of left superior vena cava to coronary sinus and unroofing of the coronary sinus $(\mathrm{n}=1)$, and augmentation of the superior vena cava to pulmonary artery anastomosis $(\mathrm{n}=1)$.

There were no statistically significant differences between intervention and control groups in the postoperative parameters of time to extubation, number of days on inotropic support, number of days of chest tube drainage, length of stay in the intensive care unit, or length of hospital stay.

\section{Outcome Measures}

Test of conduction across the interventional incision area. The test of conduction across the interventional incision was a measurement of the adequacy of the incision to block atrial conduction. There was a statistically significant difference between this measurement in the intervention group (median conduction time of $97 \mathrm{~ms}$, range 35-160) compared with the control group (median conduction time $40 \mathrm{~ms}$, range $8-77 ; P=.0001$ ). (See Figure 2.) Of the 21 intervention patients, the interventional incision was extended to the right atrioventricular groove with a cryothermal lesion in 17 patients and with dissection in 4 . The test of conduction measurement overlapped with the control group in 6 intervention patients, 3 of whom had an intervention that included a cryothermal lesion and 3 whom had an intervention with simple dissection.

Spontaneous or inducible IART. See Tables 3 and 4. No patients in the intervention group had spontaneous or inducible IART. Rarely, patients in the control group had spontaneous clinical IART $(\mathrm{n}=1)$ or inducible IART $(\mathrm{n}=$ 1). Treatment in both instances consisted of atrial pace conversion. Electrophysiologic parameters as measured at baseline or on isoproterenol and defined at postoperative atrial stimulation study were not different between groups.

Other supraventricular tachycardia. Of the intervention patients, $1(4.8 \%)$ had atypical atrioventricular node reentry and was treated with digoxin and sotalol. Of the 
TABLE 2. Comparisons of baseline cardiac parameters between intervention and control groups

\begin{tabular}{|c|c|c|c|}
\hline & $\begin{array}{l}\text { Intervention } \\
(\mathrm{n}=\mathbf{2 1})\end{array}$ & $\begin{array}{c}\text { Control } \\
(n=21)\end{array}$ & $P$ \\
\hline \multicolumn{4}{|l|}{ Electrophysiologic parameters } \\
\hline History of intra-atrial reentrant tachycardia & 0 & 0 & 1.00 \\
\hline History of other supraventricular tachycardia & 0 & 2 & .49 \\
\hline Prior pacemaker & 1 & 0 & 1.00 \\
\hline Baseline heart rate by electrocardiogram (beats/min) & $103 \pm 20$ & $102 \pm 20$ & .89 \\
\hline \multicolumn{4}{|l|}{ Echocardiographic parameters } \\
\hline \multicolumn{3}{|l|}{ Atrioventricular valve regurgitation } & .09 \\
\hline None & 15 & 20 & \\
\hline Mild & 6 & 1 & \\
\hline \multicolumn{3}{|l|}{ Ventricular function } & .61 \\
\hline Normal & 18 & 20 & \\
\hline Mildly depressed & 3 & 1 & \\
\hline \multicolumn{4}{|l|}{ Catheterization parameters } \\
\hline Systemic oxygen saturation (\%) & $83 \pm 5$ & $84 \pm 3$ & .31 \\
\hline Atrial pressure $(\mathrm{mm} \mathrm{Hg})$ & $6 \pm 3$ & $6 \pm 3$ & .83 \\
\hline Ventricular end-diastolic pressure $(\mathrm{mm} \mathrm{Hg})$ & $8 \pm 2$ & $9 \pm 4$ & .38 \\
\hline Pulmonary vascular resistence (Wood units) & $2.1 \pm 0.9$ & $1.9 \pm 0.6$ & .40 \\
\hline Cardiac index & $3.1 \pm 0.9$ & $3.5 \pm 0.8$ & .14 \\
\hline
\end{tabular}

Values shown are mean \pm SD.

patients in the control group, $3(14 \%)$ had other supraventricular tachycardias. One patient had a single episode of regular narrow complex tachycardia that terminated with adenosine and required no further medication or intervention. A second patient had complex tachycardia mechanisms, likely atypical atrioventricular node reentry, and was treated with amiodarone. The third patient had been treated for ectopic atrial tachycardia preoperatively and had ectopic atrial tachycardia again in the postoperative setting and was treated with propranolol.

Sinus node dysfunction and the requirement for pacing. A high percentage of patients in both groups demonstrated sinus node dysfunction at $>24$ hours postoperatively, with $38 \%$ of the intervention group and $29 \%$ of control group $(P=.51)$. Sinus node dysfunction largely resolved by hospital discharge, with only $10 \%$ of intervention patients and $5 \%$ of controls having sinus node dysfunction at discharge. Two patients in the intervention group required new permanent pacing, 1 for complete atrioventricular block in a patient with L-looped ventricles and 1 for slow sinus rhythm and frequent premature ventricular beats. No patients in the control group required new permanent pacing.

\section{Safety Assessment}

In the intervention group, 7 adverse events occurred in 3 patients and included: urgent fenestration closure in the catheterization laboratory $(\mathrm{n}=1)$, urgent fenestration creation in the catheterization laboratory $(\mathrm{n}=1)$, transient isolated sinus node $(\mathrm{n}=1)$, readmission for effusions $(\mathrm{n}=$ $1)$, extracorporeal membrane oxygenation $(n=1)$, multisystem failure $(\mathrm{n}=1)$, and death $(\mathrm{n}=1)$. Only 1 adverse event was evaluated to be probably attributed to the inter- vention. This was a patient who had a transient functionally isolated sinus node during the postoperative course but with recovery of conduction across the atrium prior to discharge. No permanent pacemaker was required. The 1 death was assessed by our safety panel as not being associated with the intervention. This was an 11-month-old who was considered a high-risk Fontan candidate based on preoperative hemodynamics and the presence of arteriovenous malformations.

In the control group, 9 adverse events occurred in 6 patients and included: open chest for evacuation of $\operatorname{clot}(\mathrm{n}=$ $1)$, increased liver function tests $(\mathrm{n}=1)$, decreased renal function $(\mathrm{n}=1)$, long intubation course/pulmonary issues $(\mathrm{n}=1)$, urgent fenestration creation in the catheterization laboratory $(\mathrm{n}=1)$, fungal infection $(\mathrm{n}=1)$, and readmission for chylous effusions $(n=1)$.

\section{Discussion}

The objective of this trial was to assess feasibility, safety, and short-term efficacy of an interventional atrial incision placed at the time of the initial Fontan operation to reduce postoperative IART. To our knowledge, this is 1 of 2 randomized controlled trials of surgical prophylaxis of IART in the Fontan population. ${ }^{21}$ The rationale for the interventional atrial incision was that it would create intraatrial conduction block to prevent IART circuits from developing around the atriotomy and right atrioventricular annulus. The interventional incision was modeled after similar prophylactic incisions that had been shown to be efficacious in canine Fontan models. Through this trial, we demonstrated that the interventional incision could be 


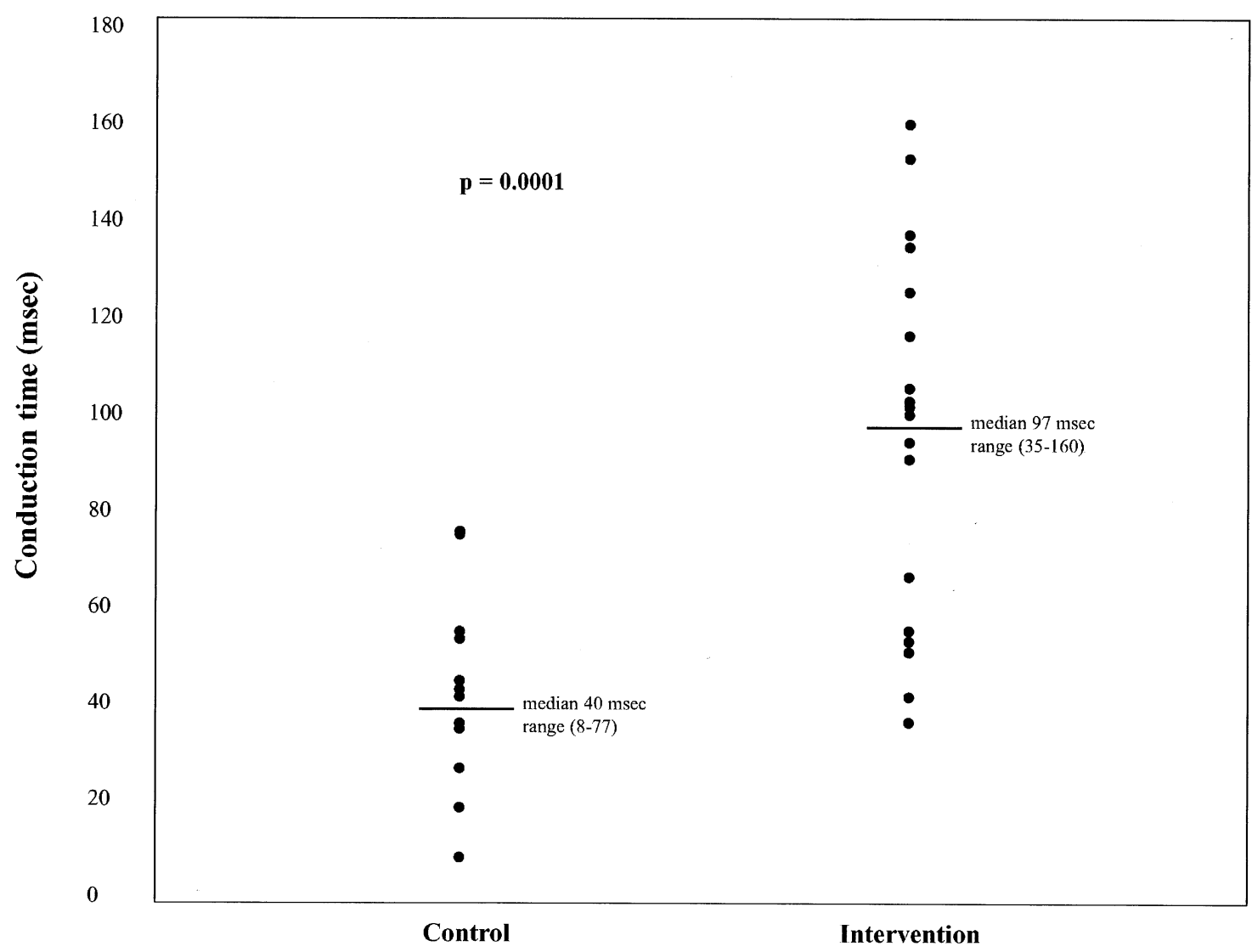

Figure 2. Graph showing the test of conduction across the atrium in the area of the interventional incision in both control and intervention groups. As would be expected if the interventional atrial incision resulted in conduction block, the measurement of conduction across the area was significantly longer in the intervention group compared to the control group.

placed in all patients randomized to the intervention group and that conduction block across the area could be achieved. The intervention was safe for patients, as the number and severity of adverse events documented were similar in both control and intervention groups. Short-term efficacy showed no difference between groups with respect to spontaneous or inducible IART. However, in contrast to animal studies of the lateral tunnel Fontan ${ }^{18,22}$ and previous reports of IART inducibility in patients with classical Fontans, ${ }^{23}$ there was a very low incidence of spontaneous or inducible IART in either group $(0 \%$ in the intervention group and $9.5 \%$ in controls). Sinus node dysfunction was evident in both groups in the immediate postoperative period but largely resolved by hospital discharge.

\section{Feasibility and Safety}

We found that the interventional atrial incision was feasible in all patients randomized to the intervention group. No patient who underwent a lateral tunnel Fontan operation was excluded from the study on the basis of anatomy. Placing the interventional incision in patients with dextrocardia with very posterior Fontan baffles was noted to be quite challenging but that it could be accomplished. Safety parameters showed that the interventional atrial incision did not prolong bypass or crossclamp times, lengthen recovery, or affect morbidity or mortality.

\section{Short-Term Efficacy}

By evaluation of conduction across the interventional incision area, we showed that the interventional atrial incision effectively created a line of conduction block. In 6 of the 21 intervention patients, however, the conduction times were shorter and overlapped with the control group, suggesting that the interventional incision was not complete and some conduction across the area remained intact. In analyzing this subgroup of intervention patients, we found that part (3 of the 6) could be explained by the interventional incision being created by careful dissection and without the use of a cryothermal lesion to complete the line to the atrioventricular annulus. Of note, only a minority of patients (4 of 21) had interventions including simple dissection to the atrioventricular annulus, with the majority having interventions 
TABLE 3. Comparisons of cardiac rhythm outcome measures between intervention and control groups

\begin{tabular}{|c|c|c|c|}
\hline & $\begin{array}{c}\text { Intervention } \\
(\mathbf{n}=\mathbf{2 1})\end{array}$ & $\begin{array}{l}\text { Control } \\
(n=21)\end{array}$ & $\boldsymbol{P}$ \\
\hline Clinical intra-atrial reentrant tachycardia & 0 & $1(5 \%)$ & 1.00 \\
\hline Inducible intra-atrial reentrant tachycardia & 0 & $1(5 \%)$ & 1.00 \\
\hline Other supraventricular tachycardia & $1(4.8 \%)$ & $3(14 \%)$ & .61 \\
\hline Temporary atrial pacing & $12(57 \%)$ & $8(38 \%)$ & .35 \\
\hline New permanent pacemaker & $2(10 \%)$ & 0 & .49 \\
\hline \multicolumn{4}{|l|}{ Sinus node dysfunction } \\
\hline$<24$ hours postoperatively & $10(48 \%)$ & $6(29 \%)$ & .34 \\
\hline$>24$ hours postoperatively & $8(38 \%)$ & $5(24 \%)$ & .51 \\
\hline At hospital discharge & $2(10 \%)$ & $1(5 \%)$ & 1.00 \\
\hline \multicolumn{4}{|l|}{ Electrocardiogram at hospital discharge } \\
\hline Heart rate & $114 \pm 23$ & $126 \pm 18$ & .07 \\
\hline Sinus & 18 & 19 & \\
\hline Junctional & 1 & 1 & \\
\hline Paced & 1 & 0 & \\
\hline
\end{tabular}

Values are number of patients (percent of group) with the given parameter.

TABLE 4. Comparison of postoperative atrial stimulation study between intervention and control groups

\begin{tabular}{|c|c|c|c|}
\hline & $\begin{array}{l}\text { Intervention } \\
(n=19 \text { of } 21)\end{array}$ & $\begin{array}{c}\text { Control } \\
(n=19 \text { of } 21)\end{array}$ & $\boldsymbol{P}$ \\
\hline $\begin{array}{l}\text { Days postoperatively that the study was conducted } \\
\text { Baseline }\end{array}$ & $5(1-40)$ & $6(2-22)$ & .30 \\
\hline Atrial effective refractory period & $200(130-230)$ & $185(160-290)$ & .65 \\
\hline $\begin{array}{l}\text { Atrioventricular nodal refractory period } \\
\text { Measured } \\
\text { Not encountered }\end{array}$ & $\begin{array}{c}266(210-390) \\
n=5 \\
n=14\end{array}$ & $\begin{array}{c}235(200-320) \\
n=6 \\
n=13\end{array}$ & .40 \\
\hline $\begin{array}{l}\text { Wenckebach cycle length } \\
\text { Isoproterenol } 0.01 \mu \mathrm{g} \cdot \mathrm{kg}^{-1} \cdot \mathrm{min}^{-1}\end{array}$ & $235(190-300)$ & $210(180-300)$ & .32 \\
\hline Atrial effective refractory period & $190(160-210)$ & $190(130-250)$ & .42 \\
\hline $\begin{array}{l}\text { Atrioventricular nodal refractory period } \\
\text { Measured } \\
\text { Not encountered }\end{array}$ & $\begin{array}{c}258(210-380) \\
n=5 \\
n=14\end{array}$ & $\begin{array}{c}220(210-230) \\
n=5 \\
n=11\end{array}$ & .26 \\
\hline Wenckebach cycle length & $210(190-300)$ & $205(190-300)$ & .32 \\
\hline Inducible intra-atrial reentrant tachycardia & $\mathrm{n}=0$ & $\mathrm{n}=1$ & 1.00 \\
\hline
\end{tabular}

Data presented are median (range) or number of patients in each category.

that included a cryothermal lesion (17 of 21$)$. Without a cryothermal lesion, there potentially could be strands of atrial tissue still intact and thus the ability to conduct across the area. The remainder ( 3 of the 6 ) of intervention patients that overlapped with the control group in this measurement can only be explained by the interventional lesion not being completely created to the atrioventricular groove, despite the use of a cryothermal lesion. Creation of a long-lasting and complete line of conduction block by surgical methods may not be effective in all cases.

\section{Early IART Following the Fontan Operation in Canine Models and in Humans}

In canine models of IART in the Fontan operation, ${ }^{19,24,25}$ IART was able to be induced with atrial pacing at baseline or with the addition of isoproterenol in all animals studied.
In a study of human patients after the Fontan operation, ${ }^{26}$ IART was inducible in $30 \%$ of patients in the baseline state without isoproterenol. The Fontan repairs in this study, however, included atriopulmonary connections and other historical modifications. In more recent retrospective reviews of Fontan patients, ${ }^{3,27,28}$ postoperative arrhythmias have been documented in $10 \%$ to $30 \%$ of patients. Within those studies, if only early postoperative IART is evaluated, then the percentage decreases to $1 \%$ to $8 \%$ of patients.

In our study, we had a very low incidence of IART, spontaneously or inducible, in both groups despite utilizing a standard atrial stimulation protocol, including the use of isoproterenol. The difference between our findings and those from prior canine or human studies may be attributable to several factors. First, the lateral tunnel Fontan baffle has had several modifications over the years and, in its 
current form, may be less arrhythmogenic than prior Fontan operations. ${ }^{13}$ Possible explanations for improved arrhythmia outcome are the surgical technique and the location of the lateral tunnel suture line in relation to the crista terminalis. ${ }^{18}$ In all of our study patients, the lateral aspect of the Fontan baffle was placed anterior and medial to the crista terminalis. Second, this is one of the first studies ${ }^{21}$ to conduct atrial stimulation studies in the immediate postoperative period in the Fontan population. Several natural history studies have shown that the prevalence of IART increases with time from the Fontan operation, ${ }^{1-3,15,27}$ suggesting that other factors such as atrial hypertrophy or fibrosis may need to occur for IART to develop. Atrial remodeling occurs with atrial tachycardia and depends on the underlying cardiac substrate. ${ }^{29}$ Third, the canine models of IART in the Fontan operation may not adequately represent the acute human substrate of IART. It is also possible that, in contrast to animal studies, Fontan suture lines constructed in surgical procedures in humans are not dense barriers to atrial conduction and thus not an important substrate for IART.

No patient in the intervention group developed IART while 2 patients in the control group had spontaneous $(\mathrm{n}=$ 1) and inducible $(n=1)$ IART, a difference that was not statistically significant. If the incidence of early spontaneous and inducible IART is in fact approximately $10 \%$ in control patients and near zero in intervention patients, as suggested by this study, it would require about 186 randomized patients to determine a beneficial effect of the interventional incision, suggesting the need for a multi-institutional study. The true potential clinical importance of the interventional incision is not in the short-term but in the efficacy at 5 to 10 years after the procedure when clinical IART is most likely to develop. Long-term follow-up of this cohort of patients is ongoing.

\section{Sinus Node Dysfunction}

We found a high percentage of short-term sinus node dysfunction in both groups, which resolved prior to hospital discharge. This finding may be a result of a broad definition of sinus node dysfunction. Any patient who had a faster junctional rhythm in the postoperative period and required atrial pacing was considered to have short-term sinus node dysfunction. Many patients required temporary atrial pacing in the postoperative time period. By hospital discharge, however, these findings resolved and most patients were in sinus rhythm with chronotropic competence.

\section{Conclusions}

An interventional atrial incision in the Fontan operation to reduce IART did not prolong bypass or crossclamp times, lengthen recovery, or affect morbidity. The interventional incision changed the atrial substrate as shown by an increase in conduction time across the area. Short-term results showed low incidence of early postoperative IART in all patients included in this trial. Longer follow-up is necessary to assess the true efficacy of the interventional incision in preventing spontaneous clinical IART.

Part of this work was done while Dr Kathryn K Collins was the Tommy Kaplan Fellow in the Children's Hospital Cardiovascular Program, Boston, and while Dr Edward K Rhee was senior electrophysiology fellow at Children's Hospital, Boston. The authors would like to thank Kimberlee Gauvreau, $\mathrm{ScD}$, of Children's Hospital, Boston, for assistance with study design, randomization and blinding, and statistical analysis.

\section{References}

1. Fishberger SB, Wernovsky G, Gentles TL, et al. Factors that influence the development of atrial flutter after the Fontan operation. $J$ Thorac Cardiovasc Surg. 1997;113:80-6.

2. Gelatt M, Hamilton RM, McCrindle BW, et al. Risk factors for atrial tachyarrhythmias after the Fontan operation. J Am Coll Cardiol. 1994; 24:1735-41.

3. Gewillig M, Wyse RK, de Leval MR, Deanfield JE. Early and late arrhythmias after the Fontan operation: predisposing factors and clinical consequences. Br Heart J. 1992;67:72-9.

4. Triedman JK, Alexander ME, Love BA, et al. Influence of patient factors and ablative technologies on outcomes of radiofrequency ablation of intra-atrial re-entrant tachycardia in patients with congenital heart disease. J Am Coll Cardiol. 2002;39:1827-35.

5. Feld GK, Fleck RP, Chen PS, et al. Radiofrequency catheter ablation for the treatment of human type 1 atrial flutter. Identification of a critical zone in the reentrant circuit by endocardial mapping techniques. Circulation. 1992;86:1233-40.

6. Balaji S, Johnson TB, Sade RM, Case CL, Gillette PC. Management of atrial flutter after the Fontan procedure. J Am Coll Cardiol. 1994;23: 1209-15.

7. Triedman JK, Saul JP, Weindling SN, Walsh EP. Radiofrequency ablation of intra-atrial reentrant tachycardia after surgical palliation of congenital heart disease. Circulation. 1995;91:707-14.

8. Triedman JK, Jenkins KJ, Colan SD, Saul JP, Walsh EP. Intra-atrial reentrant tachycardia after palliation of congenital heart disease: characterization of multiple macroreentrant circuits using fluoroscopically based three-dimensional endocardial mapping. J Cardiovasc Electrophysiol. 1997;8:259-70.

9. Deal BJ, Mavroudis C, Backer CL, Johnsrude CL, Rocchini AP. Impact of arrhythmia circuit cryoablation during Fontan conversion for refractory atrial tachycardia. Am J Cardiol. 1999;83:563-8.

10. Mavroudis C, Backer CL, Deal BJ, Johnsrude CL. Fontan conversion to cavopulmonary connection and arrhythmia circuit cryoblation. J Thorac Cardiovasc Surg. 1998;115:547-56.

11. Mavroudis C, Deal BJ, Backer CL, Johnsrude CL. The favorable impact of arrhythmia surgery on total cavopulmonary artery Fontan conversion. Semin Thorac Cardiovasc Surg. 1999;2:143-56.

12. Mavroudis C, Backer CL, Deal BJ, Johnsrude C, Strasburger J. Total cavopulmonary conversion and maze procedure for patients with failure of the Fontan operation. J Thorac Cardiovasc Surg. 2001;122:86371 .

13. Stamm C, Friehs I, Mayer JE Jr, et al. Long-term results of the lateral tunnel Fontan operation. J Thorac Cardiovasc Surg. 2001;121:28-41.

14. Azakie A, McCrindle BW, Van Arsdell G, et al. Extracardiac conduit versus lateral tunnel cavopulmonary connections at a single institution: impact on outcomes. J Thorac Cardiovasc Surg. 2001;122:1219-28.

15. Cecchin F, Johnsrude CL, Perry JC, Friedman RA. Effect of age and surgical technique on symptomatic arrhythmias after the Fontan procedure. Am J Cardiol. 1995;76:386-91.

16. Pearl JM, Laks H, Stein DG, Drinkwater DC, George BL, Williams RG. Total cavopulmonary anastomosis versus conventional modified Fontan procedure. Ann Thorac Surg. 1991;52:189-96. 
17. de Leval MR, Kilner P, Gewillig M, Bull C. Total cavopulmonary connection: a logical alternative to atriopulmonary connection for complex Fontan operations. Experimental studies and early clinical experience. J Thorac Cardiovasc Surg. 1988;96:682-95.

18. Gandhi SK, Bromberg BI, Rodefeld MD, et al. Lateral tunnel suture line variation reduces atrial flutter after the modified Fontan operation. Ann Thorac Surg. 1996;61:1299-309.

19. Rodefeld MD, Gandhi SK, Huddleston CB, et al. Anatomically based ablation of atrial flutter in an acute canine model of the modified Fontan operation. J Thorac Cardiovasc Surg. 1996;112:898-907.

20. Cohen MI, Wernovsky G, Vetter VL, et al. Sinus node function after a systematically staged Fontan procedure. Circulation. 1998;98: II352-8 (discussion II358-9).

21. Law IH, Fischbach PS, Hartman JV, et al. Early results from a prospective, double-blind, randomized trial investigating a surgical strategy to prevent intra-atrial reentrant tachycardia in the Fontan population [abstract]. PACE. 2000;23:598.

22. Rodefeld MD, Bromberg BI, Schuessler RB, Boineau JP, Cox JL, Huddleston CB. Atrial flutter after lateral tunnel construction in the modified Fontan operation: a canine model. J Thorac Cardiovasc Surg. 1996;111:514-26.
23. Kurer CC, Tanner CS, Norwood WI, Vetter VL. Perioperative arrhythmias after Fontan repair. Circulation. 1990;82:IV190-4.

24. Gandhi SK, Bromberg BI, Schuessler RB, et al. Characterization and surgical ablation of atrial flutter after the classic Fontan repair. Ann Thorac Surg. 1996;61:1666-78 (discussion 1678-9).

25. Bromberg BI, Schuessler RB, Gandhi SK, Rodefeld MD, Boineau JP, Huddleston CB. A canine model of atrial flutter following the intraatrial lateral tunnel Fontan operation. J Electrocardiol. 1998;30:S8593.

26. Kurer CC, Tanner CS, Vetter VL. Electrophysiologic findings after Fontan repair of functional single ventricle. J Am Coll Cardiol. 1991; 17:174-81.

27. Durongpisitkul K, Porter CJ, Cetta F, et al. Predictors of early- and late-onset supraventricular tachyarrhythmias after Fontan operation. Circulation. 1998;98:1099-107.

28. Gardiner HM, Dhillon R, Bull C, de Leval MR, Deanfield JE. Prospective study of the incidence and determinants of arrhythmia after total cavopulmonary connection. Circulation. 1996;94:II17-21.

29. Shinagawa K, Li D, Leung TK, Nattel S. Consequences of atrial tachycardia-induced remodeling depend on the preexisting atrial substrate. Circulation. 2002;105:251-7. 